\title{
Editorial: Red Blood Cell Vascular Adhesion and Deformability
}

\author{
Helene Guizouarn ${ }^{1 \dagger}$ and Gregory Barshtein ${ }^{2 * \dagger}$ \\ ${ }^{1}$ CNRS laboratory Institut Biology Valrose, Nice, France, ${ }^{2}$ Department of Biochemistry, The Faculty of Medicine, The Hebrew \\ University of Jerusalem, Jerusalem, Israel
}

Keywords: RBC - red blood cell, RBC deformability, RBC deformation and aggregation, RBC adhesion, erythrocyte

\section{Editorial on the Research Topic}

\section{Red Blood Cell Vascular Adhesion and Deformability}

In the present Research Topic, the red blood cell (RBC) flow-affecting properties are examined from different angles of view, revealing the complexity of these characteristics and their role in ensuring proper blood circulation.

The primary role of RBCs is the transport of respiratory gases, oxygen, and $\mathrm{CO}_{2}$, which is carried out mainly in the blood capillaries. The ability of blood to circulate is largely determined by the flow-affecting properties of RBCs (Jani et al.). Under the flow, RBCs export vasoactive mediators in response to deformation and other physiological or pathological stimuli (McMahon). This mediated response to the flow promotes efficient circulation and, in turn, optimizes gas exchanges. These flow-affecting RBC properties relate mainly to cell deformability (Depond et al.; McMahon; Semenov et al.; Lee et al.), their adherence to wall endothelial cells (ECs) (McMahon) and self-aggregation (Lazari et al.; Lee et al.).

RBC deformability refers to the ability of the cells to modify their shape to the dynamically changing flow conditions to minimize their resistance to flow and to enable their passage through small blood vessels (Jani et al.). RBC deformability has been postulated to be a significant determinant of RBCs survival (Cranston et al., 1984; Safeukui et al., 2018). In general, during cell aging (in-vivo and in-vitro) or under different pathological conditions, RBC deformability can be impaired. This phenomenon is induced by modification of cell membrane or cytosol composition and membrane structure, for instance, by the alteration of the scaffolding interactions between membrane and cytoskeleton, and the ion or water contents of RBCs (Badens and Guizouarn, 2016; Huisjes et al., 2018). This reduction of RBC deformability, may impair RBC passage and lead to splenic (Da Costa et al., 2013; Pivkin et al., 2016) and liver (Matot et al., 2013) sequestration and destruction.

RBC adherence to EC of the blood vessel walls has been considered in recent years to be a prominent catalyst of blood vessel occlusion, particularly in the microcirculation (Yedgar et al., 2008). Under healthy conditions, RBC adherence to ECs is insignificant. However, in various disorders, alterations in the RBC membrane make them adherent to EC (Montes et al., 2002; Wagner et al., 2006; Yedgar et al., 2008; Kucukal et al., 2018), and staked RBCs may block capillaries. This phenomenon has been implicated in the pathophysiology of sickle cell anemia, cerebral malaria, and thalassemia.

RBCs in the plasma aggregate to form rouleaux and rouleaux networks (Lazari et al.; Lee et al.) and the increased concentrations of acute-phase proteins, particularly fibrinogen, results in enhanced erythrocyte aggregation (Ben-Ami et al., 2003).

In addition to their own (specific) role in the blood circulation, these features also affect each other. Thus, McMahon discusses the link between RBC adhesion and deformability. While Lazari et al. analyze the relationship between RBC deformability and aggregation. Research in hemorheology is diverse, interdisciplinary, and uses both experimental and numerical methods. The articles presented in this Research Topic illustrate the diversity of these aspects. 


\section{OXIDATIVE STRESS INDUCES IMPAIRMENT OF RBC FLOW-AFFECTING PROPERTIES}

Over their lifespan, erythrocytes are regularly exposed to the oxidative stress (OS) and undergo various oxidative damages due to the high oxygen tension in arterial blood and their abundant heme iron content, etc. (Mohanty et al., 2014). Moreover, excessive production of reactive oxygen species (ROS) has been described in sickle cell anemia, thalassemia, malaria, and diabetes (Chirico and Pialoux, 2012; Kavishe et al., 2017; Almizraq et al., 2018). In turn, OS contributes to impairment of RBC flow-affecting properties (Yaribeygi et al., 2020), and as illustrated by Balushi et al., treatment with antioxidants can repair these features.

\section{FLOW-AFFECTING RBC PROPERTIES IN HEALTH AND DISEASES}

Impairment of the flow-affecting properties of human erythrocyte was associated with the pathophysiology of various diseases, such as sepsis, thalassemia, cerebral malaria, stroke, sickle cell anemia, and diabetes. This relationship has been substantiated by in-vivo and ex-vivo studies (Lee et al.).

Under normal conditions, RBC deformability allows individual cells to traverse nutritive capillaries. Decreased deformability will result in impaired perfusion and gas exchange in peripheral tissues. Hence, RBC deformability can be regarded as a potential index to diagnose specific diseases (Guo et al., 2016; Lim et al., 2018), for example, not only diabetic

\section{REFERENCES}

Almizraq, R. J., Holovati, J. L., and Acker, J. P. (2018). Characteristics of extracellular vesicles in red blood concentrates change with storage time and blood manufacturing method. Transf. Med. Hemother. 45, 185-193. doi: 10.1159/000486137

Badens, C., and Guizouarn, H. (2016). Advances in understanding the pathogenesis of the red cell volume disorders. Br. J. Haematol. 174, 674-685. doi: 10.1111/bjh.14197

Barshtein, G., Arbell, D., Livshits, L., and Gural, A. (2018). Is it possible to reverse the storage-induced lesion of red blood cells? Front. Physiol. 9:914. doi: 10.3389/fphys.2018.00914

Ben-Ami, R., Barshtein, G., Mardi, T., Deutch, V., Elkayam, O., Yedgar, S., et al. (2003). A synergistic effect of albumin and fibrinogen on immunoglobulininduced red blood cell aggregation. Am. J. Physiol. Heart Circ. Physiol. 285, H2663-H2669. doi: 10.1152/ajpheart.00128.2003

Chirico, E. N., and Pialoux, V. (2012). Role of oxidative stress in the pathogenesis of sickle cell disease. IUBMB Life 64, 72-80. doi: 10.1002/iub.584

Cranston, H. A., Boylan, C. W., Carroll, G. L., Sutera, S. P., Williamson, J. R., Gluzman, I. Y., et al. (1984). Plasmodium falciparum maturation abolishes physiologic red cell deformability. Science 223, 400-403. doi: $10.1126 /$ science.6362007

Da Costa, L., Galimand, J., Fenneteau, O., and Mohandas, N. (2013). Hereditary spherocytosis, elliptocytosis, and other red cell membrane disorders. Blood Rev. 27, 167-178. doi: 10.1016/j.blre.2013.04.003

Guo, Q., Duffy, S. P., Matthews, K., Deng, X., Santoso, A. T., Islamzada, E., et al. (2016). Deformability based sorting of red blood cells improves diagnostic kidney disease but also other diabetes-related complications (Lee et al.).

\section{METHODS FOR CHARACTERIZATION OF RBCs FLOW-AFFECTING PROPERTIES}

Most of the relevant studies have been provided by under invitro conditions (Ben-Ami et al., 2003; Relevy et al., 2008; Barshtein et al., 2018; Lee et al., 2018; Zaninoni et al., 2018; Zhu et al., 2020), but Jani et al. estimate the erythrocyte mechanical properties in-vivo during capillary plug flow. To characterize the mechanical properties of red blood cells, the authors (Jani et al.) combined the capabilities of intravascular microscopy with numerical simulation. Spectrum of in-vitro techniques that can be used for characterization of RBCs flow-affecting properties is very broad. This list includes laser ektacytometry (Semenov et al.; Lee et al.), laser tweezers (Lee et al., 2018; Zhu et al., 2020), atomic force microscopy (Steffen et al., 2013), microfluidics (Ben-Ami et al., 2003; Relevy et al., 2008; Guo et al., 2016; Barshtein et al., 2018; Lee et al., 2018; Lim et al., 2018). In this Research Topic, Depond et al. discuss the usefulness of these methods for the characterization of the RBC deformability for malaria patients.

Thus, we can conclude that the features discussed above can act independently and synergistically, affecting blood circulation, and thus, their deterioration can be considered as a powerful catalyst for circulatory disorders.

\section{AUTHOR CONTRIBUTIONS}

All authors listed have made a substantial, direct and intellectual contribution to the work, and approved it for publication. sensitivity for malaria caused by Plasmodium falciparum. Lab Chip 16, 645-654. doi: 10.1039/C5LC01248A

Huisjes, R., Bogdanova, A., Van Solinge, W. W., Schiffelers, R. M., Kaestner, L., and Van Wijk, R. (2018). Squeezing for life - properties of red blood cell deformability. Front. Physiol. 9:656. doi: 10.3389/fphys.2018. 00656

Kavishe, R. A., Koenderink, J. B., and Alifrangis, M. (2017). Oxidative stress in malaria and artemisinin combination therapy: pros and cons. FEBS J. 284, 2579-2591. doi: 10.1111/febs.14097

Kucukal, E., Little, J. A., and Gurkan, U. A. (2018). Shear dependent red blood cell adhesion in microscale flow. Integr. Biol. 10, 194-206. doi: 10.1039/C8IB00004B

Lee, K., Shirshin, E., Rovnyagina, N., Yaya, F., Boujja, Z., Priezzhev, A., et al. (2018). Dextran adsorption onto red blood cells revisited: single cell quantification by laser tweezers combined with microfluidics. Biomed. Opt. Express 9, 2755-2764. doi: 10.1364/BOE.9.002755

Lim, H., Back, S. M., Nam, J., and Choi, H. (2018). Determination of red blood cell deformability using centrifugal force in a three-dimensional-printed mini-disk (3D-PMD). PLoS ONE 13:e0197619. doi: 10.1371/journal.pone.0197619

Matot, I., Katz, M., Pappo, O., Zelig, O., Corchia, N., Yedgar, S., et al. (2013). Resuscitation with aged blood exacerbates liver injury in a hemorrhagic rat model. Crit. Care Med. 41, 842-849. doi: 10.1097/CCM.0b013e3182711b38

Mohanty, J. G., Nagababu, E., and Rifkind, J. M. (2014). Red blood cell oxidative stress impairs oxygen delivery and induces red blood cell aging. Front. Physiol. 5:84. doi: 10.3389/fphys.2014.00084

Montes, R. A., Eckman, J. R., Hsu, L. L., and Wick, T. M. (2002). Sickle erythrocyte adherence to endothelium at low shear: role of shear stress in propagation of vaso-occlusion. Am. J. Hematol. 70, 216-227. doi: 10.1002/ajh.10145 
Pivkin, I. V., Peng, Z., Karniadakis, G. E., Buffet, P. A., Dao, M., and Suresh, S. (2016). Biomechanics of red blood cells in human spleen and consequences for physiology and disease. Proc. Natl. Acad. Sci. U.S.A. 113, 7804-7809. doi: $10.1073 /$ pnas. 1606751113

Relevy, H., Koshkaryev, A., Manny, N., Yedgar, S., and Barshtein, G. (2008). Blood banking-induced alteration of red blood cell flow properties. Transfusion 48, 136-146. doi: 10.1111/j.1537-2995.2007. 01491.x

Safeukui, I., Buffet, P. A., Deplaine, G., Perrot, S., Brousse, V., Sauvanet, A., et al. (2018). Sensing of red blood cells with decreased membrane deformability by the human spleen. Blood Adv. 2, 2581-2587. doi: 10.1182 /bloodadvances.2018024562

Steffen, P., Verdier, C., and Wagner, C. (2013). Quantification of depletioninduced adhesion of red blood cells. Phys. Rev. Lett. 110:018102. doi: 10.1103/PhysRevLett.110.018102

Wagner, M. C., Eckman, J. R., and Wick, T. M. (2006). Histamine increases sickle erythrocyte adherence to endothelium. Br. J. Haematol. 132, 512-522. doi: $10.1111 / j .1365-2141.2005 .05880 . x$

Yaribeygi, H., Sathyapalan, T., Atkin, S. L., and Sahebkar, A. (2020). Molecular mechanisms linking oxidative stress and diabetes mellitus. Oxid. Med. Cell. Longev. 2020:8609213. doi: 10.1155/2020/86 09213
Yedgar, S., Kaul, D. K., and Barshtein, G. (2008). RBC adhesion to vascular endothelial cells: more potent than RBC aggregation in inducing circulatory disorders. Microcirculation 15, 581-583. doi: 10.1080/10739680802105482

Zaninoni, A., Fermo, E., Vercellati, C., Consonni, D., Marcello, A. P., Zanella, A., et al. (2018). Use of laser assisted optical rotational cell analyzer (LoRRca MaxSis) in the diagnosis of RBC membrane disorders, enzyme defects, and congenital dyserythropoietic anemias: a monocentric study on 202 patients. Front. Physiol. 9:451. doi: 10.3389/fphys.2018.00451

Zhu, R., Avsievich, T., Popov, A., and Meglinski, I. (2020). Optical tweezers in studies of red blood cells. Cells 9:545. doi: 10.3390/cells9030545

Conflict of Interest: The authors declare that the research was conducted in the absence of any commercial or financial relationships that could be construed as a potential conflict of interest.

Copyright (C) 2020 Guizouarn and Barshtein. This is an open-access article distributed under the terms of the Creative Commons Attribution License (CC BY). The use, distribution or reproduction in other forums is permitted, provided the original author(s) and the copyright owner(s) are credited and that the original publication in this journal is cited, in accordance with accepted academic practice. No use, distribution or reproduction is permitted which does not comply with these terms. 